\title{
Breastfeeding Knowledge, Attitude, and Practices among Mothers Attending Health Centers in Sana'a City
}

\author{
Abdulsalam Mohammed Dallak ${ }^{1}$, Nabil Ahmed Al-Rabeei ${ }^{2}$, Yassein Ahmed Aljahmi ${ }^{3}$ \\ Faculty of Medicine and Health Sciences, Sana'a University ${ }^{1,2,3}$ \\ ${ }^{2}$ nabilalrabeei@hotmail.com
}

\begin{abstract}
:
Introduction: Inadequate knowledge, or inappropriate practice, of breastfeeding may lead to undesirable consequences.

Objective: The aim of this study was to assess breastfeeding knowledge, attitude and practice among mothers attending to MCHC in Sana'a city.

Methods: A descriptive cross-sectional study of 374 mothers with baby less than 2 years age was conducted in the 20 of MCHC in Sana'a city, between February and June 2012. A multistage random sampling was used. By structured questionnaire and interview, data were collected about demographic characteristics of mothers and their current baby, mother's knowledge, attitude and practices toward breastfeeding, reasons for breastfeeding and the source of breastfeeding information. Mean $\pm S D$ and median. Kruskal Wallis and Mann-Whitney test were used to assess association between variables.

Result: Mothers had inadequate knowledge and neutral attitude toward breastfeeding, the mean IIFAS score was (56.17; SD: 6.91). Initiation of breastfeeding within one hour was $36.4 \%$ and exclusive breastfeeding was $39.9 \%$. There was significant association found between mothers' knowledge and attitude toward breastfeeding with their education, occupation and habits ( $P$ value $<0.05)$. Association between breastfeeding practices and mother's habits found ( $P$ value <0.05).
\end{abstract}

Conclusion: Inadequate of mother's knowledge, neutral attitude and there was a gap between actual and desired breastfeeding practices. It is important to provide accurate prenatal education that focuses on methods and long-term benefits of infant feeding to mothers, family and health professionals.

Keyword: breastfeeding, knowledge, attitude, practices, Yemen.

\section{INTRODUCTION}

Breastfeeding is an important public health strategy for improving infant and child morbidity and mortality, improving maternal morbidity, and helping to control health care costs. Breastfeeding is associated with a reduced risk of otitis media, gastroenteritis, respiratory illness, sudden infant death syndrome, necrotizing enterocolitis, obesity, and hypertension [1]. The World Health Organization (WHO) and United Nations Children's Fund (UNICEF) recommend that every infant should be exclusively breastfed for the first six months of life, with breastfeeding continuing for up to two years of age or longer[2]. Variables that may influence breastfeeding include race, maternal age, maternal employment, level of education of parents, socio-economic status, insufficient milk supply, infant health problems, maternal obesity, smoking, parity, method of delivery, maternal interest and other related factors [3]. Only 35\% of worldwide infants were exclusively breastfed for even the first six months of life and the recommendations in developing countries were still low[4]. Exclusive breastfeeding is extremely uncommon and breastfeeding practices in Yemen are varying considerably and largely suboptimal [5,6]. The exclusively breastfed infants aged 2-3 months at 1997 were 17\% and decreased to $8 \%$ at age 4-5 months [7] and $17.7 \%$ on 2003 [8]. Only a few studies on this topic were identified in Yemen. Findings from this study could be used in developing appropriate intervention strategies to promote optimal infant feeding in Sana'a, as well as nearby governorate in Yemen.

\section{OBJECTIVE}

To assess knowledge, attitude and practices regarding breastfeeding among mothers attending the Maternal and Child Health Centers (MCHC) in Sana'a city. 


\section{Materials AND Methods}

Study Setting: MCHC in Sana'a city, Yemen were included in the present study.

Study Design: A descriptive cross-sectional survey was conducted from February to June 2015 in 10 districts in Sana'a city.

Study Participants and Sampling: A multistage random sampling was used to select 374 mothers of children aged less than two years attended the MCHC. The first stage of sampling was all districts in Sana'a city were selected. The second stage was two centers from each district were selected randomly. The third stage was 18-20 mothers were selected from each selected MCHC.The eligibility criteria for inclusion in these study were all Yemeni mothers of children aged less than two years, who attending the MCHC in Sana'a city during data collection period and agree to participate in this study were selected.The sample size was calculated using EpiCalc. The sample size (n) was 340 women plus $10 \%(\mathrm{n}=374)$.

Data Collection Technique: The structured questionnaire was implemented using face to face interview. Each mother was privately interviewed at the MCHC by the research team. The questionnaire consisted of six parts as follows; 1) demographic data of the participants,2) Breastfeeding knowledge: it consisted of 12 items that cover; initiation of breast feeding (2q), colostrum (3q), essentials for breast feeding (4q) and importance of breast feeding (3q).3) Iowa Infant Feeding Attitude Scale (IIFAS): this part was modified from Mora 1999.[9], the scale consisted of 16 items to determine level of agreement to each question, 4) infant and young child feeding practices questionnaire, this tool was modified from WHO 2010 [10]: it consisted of 6 multifunction questions according to the WHO indicators for assessing the infant and young child feeding practices. The children were classified according the WHO as follows: (Early initiation of breastfeeding rate: children born in the last 24 months and were put to the breast within one hour of birth, Breastfeeding pattern: classified as exclusive breastfeeding, predominant breastfeeding and artificial feeding according to the WHO definition and duration of breastfeeding: The length of any kinds of breastfeeding), 5) Reasons for choice breastfeeding: It consisted of 14 items and 6) Source of information about breastfeeding: this part was consisted of 14 items. Twenty subjects were selected to test the feasibility, applicability and content validity of the questionnaire. Necessary modifications were made accordingly.

Statistical Analysis: Data processing, statistical analysis and graph drawing were conducted using Statistical Package for Social Sciences software (SPSS, version 20.0, Chicago. Inc). Variables described using frequency distribution for categorical variables and mean \pm standard deviation (SD) for continuous variables. Kruskal Wallis and Mann-Whitney Tests were used to test the difference in means if data when not normal distribution. Significant considered when $P$-value of $\leq 0.05$. Questions with five-point Likert rating scale, from strongly disagree to strongly agree used to assess women's attitude to breastfeeding. The level of the knowledge scores regarding breastfeeding was categorized into 3 levels as follow: 1) Low level of knowledge included score 0-6 points, 2), moderate level of knowledge included score 7-9 points and 3) and good level of knowledge included score 10-12 points.Question items that favour formula feeding were reversed scored (i.e., $1=5,2=4$, $4=2$, and $5=1$ ). The sum of the responses was calculated to get the total IIFAS score and mean. The total IIFAS score ranged from 16 to 80 . The higher scores reflect more positive breastfeeding attitude. Total scores were grouped into: positive to breastfeeding (65-80), neutral (44-64) and positive to formula feeding (16-43).

Ethical Considerations: The study was initially approved by the local health authorities in Sana'a city.Purpose and benefits of the survey were explained to mothers. Oral informed consent has obtained from all mothers enrolled in this study.

\section{RESUlTS}

\section{Demographic Data of Study Participants}

The result of the present study showed that, nearly the half (48.9\%) of participated mothers their age ranged from 16-25 years. The mean age of the mothers was 26.6 years and SD was 4.96 years. Only $4.5 \%$ of the mothers were above 30 years. The education level of mothers indicated that, $26.2 \%$ were illiterates, compared to $(4.3 \%)$ literate, $(23.6 \%)$ basic education, $(27.5 \%)$ secondary education and 

City

$18.4 \%$ had university education and above. Moreover, most of the participants (81.8\%) were housewives, $34.8 \%$ were tobacco used and $72.2 \%$ of them had less than 3 pregnancies.

\section{Mothers Knowledge Regarding Breastfeeding}

The highest correct responses $(96.0 \%)$ were regarding the "Mothers ideal body position for breast feeding", $94.9 \%$ for "Meaning of colostrum" and $90.6 \%$ for the item "When burping is performed". The lowest correct response (8.3\%) was related to the "Effect of pre-lacteal feed". About $61.2 \%$ of the correct responses were regarding the "initiation ofbreast feeding" and $61.8 \%$ to the item "content of colostrum". The majority (90.1\%) of mothers knew the "duration of colostrum secretion" and more than three quarters $(77.3 \%)$ knew the "reason for doing burping". More than two thirds (68.4\%) of the respondents, understood "the action performed when the baby is ill" and $44.7 \%$ knew "the action performed when the mother is ill" and more than one third (36.6\%) of mothers knew the meaning of exclusive breast feeding (Table 1).The levels of mother's knowledge regarding breastfeeding showed that, nearly the half of mothers $(47.3 \%)$ had moderate level of knowledge and $30.2 \%$ had low level of knowledge, while $22.5 \%$ of the mothers had high level of knowledge.

Table1. The Mothers' Correct Answers about Breastfeeding Knowledge $(N=374)$

\begin{tabular}{|c|c|c|c|}
\hline \multirow{2}{*}{\multicolumn{2}{|c|}{$\begin{array}{lc} & \text { Items }\end{array}$}} & \multicolumn{2}{|c|}{ CorrectResponse } \\
\hline & & $\mathrm{n}$ & $\%$ \\
\hline \multirow{2}{*}{$\begin{array}{l}\text { Initiation of } \\
\text { breastfeeding }\end{array}$} & Effect of pre-lacteal feed & 31 & 8.3 \\
\hline & Initiation of breast feeding & 229 & 61.2 \\
\hline \multirow[t]{3}{*}{ Colostrum } & Meaning of colostrum & 355 & 94.9 \\
\hline & Duration of colostrum secretion & 337 & 90.1 \\
\hline & Contents of colostrum & 231 & 61.8 \\
\hline \multirow{4}{*}{$\begin{array}{l}\text { Essentials of } \\
\text { breastfeeding }\end{array}$} & Mothers ideal body position for breastfeeding. & 359 & 96.0 \\
\hline & When burping is performed & 339 & 90.6 \\
\hline & Reason for doing burping & 289 & 77.3 \\
\hline & Not necessity to wash the breast before each feeding & 109 & 29.1 \\
\hline \multirow{3}{*}{$\begin{array}{l}\text { Importance of } \\
\text { breastfeeding }\end{array}$} & Action performed when the baby is ill & 256 & 68.4 \\
\hline & Action performed when the mother is ill & 167 & 44.7 \\
\hline & Meaning of exclusive breast feeding & 137 & 36.6 \\
\hline
\end{tabular}

\section{Mother's Attitude toward Breastfeeding}

The mean of total IIFAS score of all valid participants was in the neutral range (56.17; SD: 6.91). About $44.7 \%$ of the mothers were strongly agree that "Breastfeeding increases mother infant bonding" followed by $44.1 \%$ for the item "Breast milk is more easily digested than formula", then equal percentages with $(43.9 \%)$ for both"Breast milk is the ideal food for babies" and "Breastfed babies are healthier than formula fed babies" and $43.6 \%$ for the item "Breastfeeding is more convenient than formula". The highest response toward the natural attitude was $44.9 \%$ regarding the item "Breast milk is lacking in iron". The high percentage (34.5\%) of the respondents were strongly disagree about "Breastfed babies are more likely to be overfed than formula fed babies"(Table2).The mother's attitude level toward breastfeedingindicated that, the majority $(86.1 \%)$ of the participated mothers had neutralattitude toward breastfeeding compared to $12.8 \%$ of mothers who had positive attitude to breastfeeding and only $1.1 \%$ of the mothers had positive attitude toward formula feeding.

Table2. Mother's IIFAS Descriptive Statistics toward Breast Feeding $(N=374)$

\begin{tabular}{|l|l|l|l|l|l|}
\hline & $\mathrm{SA}$ & $\mathrm{A}$ & $\mathrm{Neutral}$ & $\mathrm{DA}$ & $\mathrm{SDA}$ \\
\cline { 2 - 6 } Items & $\%$ & $\%$ & $\%$ & $\%$ & $\%$ \\
\hline $\begin{array}{l}\text { The benefits of breastfeeding last only as long as the baby is } \\
\text { breastfed.* }\end{array}$ & 19.0 & 14.4 & 28.3 & 24.1 & 14.2 \\
\hline Formula feeding is more convenient than breastfeeding.* & 6.7 & 7.0 & 27.3 & 34.8 & 24.3 \\
\hline Breastfeeding increases mother infant bonding. & 43.9 & 28.3 & 17.6 & 6.1 & 4.0 \\
\hline Breast milk is lacking in iron.* & 11.0 & 13.9 & 44.9 & 16.6 & 13.6 \\
\hline Formula fed babies are more likely to be overfed than breastfed & 25.9 & 19.5 & 22.7 & 19.0 & 12.8 \\
\hline $\begin{array}{l}\text { Formula feeding is the better choice if the mother plans to go } \\
\text { back to work.* }\end{array}$ & 14.2 & 18.7 & 34.5 & 17.9 & 14.7 \\
\hline $\begin{array}{l}\text { Mothers who formula feed miss one of the great joys of } \\
\text { motherhood. }\end{array}$ & 14.7 & 13.1 & 26.5 & 28.9 & 16.8 \\
\hline
\end{tabular}


Abdulsalam Mohammed Dallak et al.

\begin{tabular}{|c|c|c|c|c|c|}
\hline Women should not breastfeed in public places.* & 16.6 & 17.4 & 27.0 & 25.4 & 13.6 \\
\hline Breastfed babies are healthier than formula fed babies. & 43.9 & 23.8 & 18.7 & 10.2 & 3.5 \\
\hline Breastfed babies are more likely to be overfed than formula fed* & 4.3 & 4.8 & 23.8 & 32.6 & 34.5 \\
\hline Fathers feel left out if a mother breast feeds.* & 11.5 & 10.7 & 29.9 & 28.6 & 19.3 \\
\hline Breast milk is the ideal food for babies. & 44.7 & 32.9 & 16.8 & 3.2 & 2.4 \\
\hline Breast milk is more easily digested than formula. & 43.6 & 30.2 & 18.2 & 5.3 & 2.7 \\
\hline Formula is as healthy for an infant as breast milk.* & 10.2 & 13.4 & 27.3 & 32.1 & 17.1 \\
\hline Breastfeeding is more convenient than formula. & 44.1 & 26.7 & 18.4 & 8.0 & 2.7 \\
\hline Breast milk is cheaper than formula. & 32.4 & 25.4 & 23.3 & 12.6 & 6.4 \\
\hline
\end{tabular}

* Variables Reverse Scored to Calculate Total Infant Feeding Attitude

\section{The Mother's Knowledge and Attitude about Breastfeeding and Demographic Data}

The results reveals that highly significant association between the mothers' knowledge scores and their education, occupation status and tobacco used $(p<0.001)$ but no statistical significant regarding mother age $(p>0.05)$. No statistically significant association between mothers attitude score and their age $(P>0.05)$.The mean attitude score of the mothers' toward breastfeeding increased as their education level increased. The mothers with high level education had the highest mean score (60.20 \pm 6.38$)$, while, illiterates had the lowest mean attitude score $(52.82 \pm 5.82)$. The difference between groups was statistically significant $(P<0.001)$. The employed mothers had higher mean attitude score $(59.89 \pm 5.66)$ than housewives mothers $(55.41 \pm 6.918)$, the difference between groups was statistically significant $(P<0.001)$. With respect to the mothers habits, mothers who neither tobacco used, had higher mean attitude score $(57.01 \pm 6.95)$ than those who are tobacco used. The difference between groups was statistically significant $(P<0.05)$.

\section{Mothers Practices Regarding Breastfeeding}

The majority (97.9\%) of mothers had ever breastfed their babies and $87.7 \%$ of them breastfed their babies during the last 24 hours. More than one third (36.4\%) of the children had their first breastfed within one hour after delivery. About 39.9\% of the children less than 6 months of age were exclusively breastfed compared to $34.8 \%$ for bottle-feeding and $19.1 \%$ for the predominant breastfeeding during the previous day. The present study showed that nearly two thirds $(61.7 \%)$ of the infants 6-8 months of age received complementary feeding during the last 24 hours. According to the duration of breastfeeding; about two thirds (63.15\%) of the children finished one year, still continue breast feeding and $50 \%$ of the babies continued breastfeeding at 2 years(Figure 1).

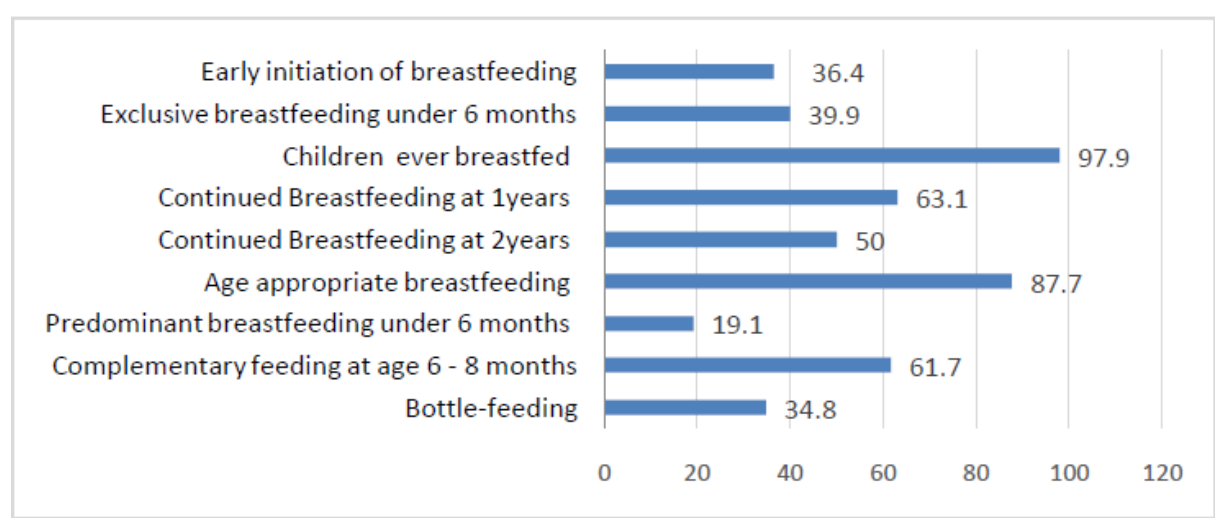

Figure1. The Indicators for Assessing Infant and Young Child Feeding Practice $(N=374)$

\section{Reasons to Choice Breastfeeding}

The most common reason mentioned by the mothers to choice breastfeeding among $75.1 \%$ of the mothers was that breastfeeding would help baby to be healthier and $72.7 \%$ of them said it "enhance baby growth". With respect to the reasons to choice breastfeeding for mothers", about $71.9 \%$ of the mothers said that breast feeding "enhance uterine involution and recovery of mother" and used it as contraceptive method. About $71.7 \%$ of the mothers' said it prevent postpartum bleeding. $70.6 \%$ of the mothers said that breastfeeding is safe for baby and promotes emotional and psychological bonding between mothers and infants, while $70.1 \%$ of mothers mentioned that, it decreased the risk of breast cancer (Table 3). 
Breastfeeding Knowledge, Attitude, and Practices among Mothers Attending Health Centers in Sana'a City

Table3. The Reasons to Choice Breastfeeding among Mothers $(N=374)$

\begin{tabular}{|l|l|c|c|}
\hline \multicolumn{1}{|c|}{ Reasons (More than one choice was allotted) } & n & \% \\
\hline For Child & Enhance baby Health & 281 & 75.1 \\
\cline { 2 - 4 } & Enhance baby growth & 272 & 72.7 \\
\cline { 2 - 4 } & Safe for baby & 264 & 70.6 \\
\cline { 2 - 4 } & Convenient for baby & 265 & 70.9 \\
\cline { 2 - 4 } & Complete nutrients & 261 & 69.8 \\
\cline { 2 - 4 } & Enhance immune system of baby & 261 & 69.8 \\
\hline For Mother & Enhance uterine involution and recoveryof mother & 269 & 71.9 \\
\cline { 2 - 4 } & Contraceptive & 269 & 71.9 \\
\cline { 2 - 4 } & Prevent postpartum bleeding & 268 & 71.7 \\
\cline { 2 - 4 } & Enhance bonding & 264 & 70.6 \\
\cline { 2 - 4 } & Decrease risk of breast cancer & 262 & 70.1 \\
\cline { 2 - 4 } & Available and no need preparation & 256 & 68.4 \\
\cline { 2 - 4 } & Save money & 211 & 56.4 \\
\cline { 2 - 4 } & Breast feeding as habit & 193 & 51.6 \\
\hline
\end{tabular}

\section{Sources of Information about Breastfeeding}

With respect to the source of information about breastfeeding, the majority of the mothers $(96.0 \%)$ received knowledge about breastfeeding from their families, and $8.8 \%$ from their friends. More than half $(55.3 \%)$ acquired knowledge from television and $21 \%$ from other media (radio, news pepper and internet). Nearly the half (49.7\%) get knowledge from Holy Quran. About $39.6 \%$ of the mothers received information from health workers. More thanone third $(35.0 \%)$ of mothers received information from education and $32.3 \%$ from printed materials.

\section{DiSCUSSION}

Generally, the overall mother's knowledge was inadequate for $60 \%$ of the participants. This result was nearly similar to that found in India, Nepal and Bangladesh. [11, 12].About one quarter of the mothers had awareness about the initiation of breast feeding; these findings were nearly similar to that found by Savitha 2005, [13]. Nearly two thirds of the participants in the present study knew that breastfeeding should be started within one hour after birth, which is higher than that found in Tanzania, [14] and in India [15]. The mothers' knowledge about the meaning of exclusive breastfeeding in this study was mentioned by more than one third of mothers, which is higher that found in Saudi Arabia [16]. These results were nearly similar with Iraqi mothers [17] and much lower than the results in USA, [18]. In this study, more than two fifths of the mothers were aware of the action performed when the mothers were ill. This result was nearly similar with other studies conducted in Saudi Arabia [19] and India [20], in which the mothers knew not to stop breastfeeding when the infant was ill. The majority of the mothers in the present study had adequate knowledge about the colostrum. This results were nearly the same with that found in Malaysia [21] and higher than that found in Iran [22].

Similar to other results, the present study indicated neutral attitudes toward breastfeeding[23, 24]. The high response rate in the neutral attitude toward breastfeeding was found in $44.9 \%$ of mothers who mentioned that "Breast milk is lacking in iron", more than a third (34.5\%) believed that "Formula fed is the better choice if the mother plans to go back to work", $29.9 \%$ of mothers mentioned that "Fathers feel left out if a mother breast feeds" and $28.3 \%$ believed that, "the benefits of breastfeeding last only as long as the baby is breastfed". In the present study $43.9 \%$ of the mothers believed that breastfed is healthier for babies. This result is higher than the results of Al-Binali 2012 (36.7\%) [16] and Khamnian 2013 with (31\%)[12].Mothers' negative attitude toward breastfeeding could be due to lack of mothers' knowledge about breast milk contents and benefits and lack of facility to support mother's breastfeeding in workplace, feel uncomfortable to breastfeed in public places, negative father's attitude toward breastfeeding, community restricted and Yemen tradition culture.

WHO recommends that breastfeeding be initiated within 1 hour of birth and initiation of breast feeding within one hour of birth was one of the ten steps to successful breastfeeding on which the BFHI was based and implemented in 1992. Only 39\% of newborns in the developing world are put to the breast within one hour of birth [25]. In the present study about $36.4 \%$ the mothers initiated 
breastfeeding within one hour after birth. This finding has almost similarity with that found in Turkey (35.2\%)[26] and in India (35.1\%)[27]. On the other hand this result is higher than that reported in Iraq $30.2 \%$ [28], and in Iran (21.3\%)[29] 18. Furthermore, this result is lower than that found in a national study (40\%) [30], and Saudi Arabia (42\%) [31]. Poor initiation breastfeeding immediately within one hour after birth could be due to younger mother's age as about $50 \%$ of the participants their age from 16-25 years. Another reason could be lack of breastfeeding experience among mothers as $72.7 \%$ of the participants had two pregnancies or less.

The mothers who breastfed their babies exclusively for less than six month of age were $39.9 \%$. This result is higher than that in Jordan 36\%[32], in Emirate 25\%,[33], and in Kuwait $10.5 \%$ of babies were exclusively breastfed for at least 6 months [34]. On the other hand this result was lower than that in Ethiopia 55.6\%[35]. In the present study the duration of breastfeeding at the first year is $63.1 \%$ and declined to $50 \%$ at the second year. This result is lower than other study conducted in Yemen, $83.5 \%$ at first year and 56.3\% at the second year [36] and Iraq 70.1\% at 1 year[37]. On the other hand, it is higher than that in Jordan 51.9\% and 10\% at the second year [38] and Iraq 33.3\% at 2 year[37]. The decline of breastfeeding rate with age proceed was could be due to mothers feel no breast milk, lack of family support or pregnancy, although the Islamic religion supported breastfeeding continuation for 2 years [16]. In this study the predominant breastfeeding rate under 6 months was (19.1\%), which is reversed to other pervious study conducted in Egypt 42.1\% [39].The complementary feeding for infant at 6-8 months age was 61.7\%, which is nearly similar to that found in Saudi Arabia[40] and much lower than that found in Tajikistan[41] for the same age group. In the current study, the bottlefeeding rate was 34.8\%, which is in line with that found in Egypt 35.7\%[39], while it is higher than that in Gaza 7.5\%[42] and lower than that found in Saudia76.1\% [43].

In relation to the breastfeeding reasons related to children, like Jordanian mothers, the child health was the main reason for which the mother's decided to breastfed their babies in about $71.4 \%$ of the participated mothers in this study, [44], while it was against Singh, 2010, in which $97 \%$ of the mothers said breastfeeding is healthier for children[45]. Other reasons mentioned by the mothers in the present study were enhancing baby growth, safe and convenient, contain complete nutrients and enhance immune system of baby. In relation to the breastfeeding reasons among mothers, the findings showed that $66.5 \%$ of the mother's practiced breastfeeding to enhance mother infant bonding, which is less than that reported byKotb, et al.[46]. The other reasons as decrease the risk of breast cancer is in line with Kotb, et al.[46] and save money is less than the results found in other studies as [47, 45].

The sources of information regarding breastfeeding, this study in line with the study results conducted among Iranians mothers [48], the family was the main source of the mother's knowledge about the breastfeeding in the present study. The religion recommendation (Holy Quran) is the second source of information as that found by Singh, 2010[45]. Against to other studies conducted in Saudi Arabia [43] and India,[49], the health personnel in the present study was ranked the last source of the mother's information about breastfeeding. That could be due to absence of breastfeeding educational programme for mothers and no policy to support breastfeeding.

\section{Conclusion}

Inadequate of mother's knowledge, neutral attitude and there was a gap between actual and desired breastfeeding practices.

\section{RECOMMENDATIONS}

It is important to provide accurate prenatal education that focuses on methods and long-term benefits of infant feeding to mothers, family and health professionals.

\section{ACKNOWLEDGEMENTS}

The authors thank the mothers who taken part in this survey.

\section{REFERENCES}

[1] James, D. C., and Rachelle Lessen. , "Promoting and supporting breastfeeding.," J Am Diet Assoc, vol. 109, no. 11, p. 1926-1942, 2009.

[2] WHO and UNICEF, "Global strategy for infant and young child feeding.," World Health Organization, Geneva, 2003. 
[3] M. Nabulsi, "Why are breastfeeding rates low in Lebanon? a qualitative study.," BMC Pediatr, vol. 11, no. 1, p. 75, 2011.

[4] J. A. Lauer, A. P. Betrán, C. G. Victora, M. de Onís and A. J. Barros, "Breastfeeding patterns and exposure to suboptimal breastfeeding among children in developing countries: review and analysis of nationally representative surveys," BMC Med, vol. 2, no. 26, 2004.

[5] WFP, "Yemen: Secondary Data Analysis on Food Security and Vulnerability," World Food Programme, 2009.

[6] O. Ecker, C. Breisinger, C. McCool, X. Diao, J. Funes, L. You and B. Yu, "Assessing Food Security in Yemen: An Innovative Integrated, Cross-Sector, and Multilevel Approach," International Food Policy Research Institute (IFPRI), 2010.

[7] YDMCHS, "Yemen Demographic and Maternal and Child Health Survey 1997," Central Statistical Organization (CSO) [Yemen], Macro International Inc., Calverton, Maryland, 1998.

[8] UNICEF, "Child Development Project Baseline Survey Results Round One and Two," UNICEF, Yemen, 2003.

[9] A. d. 1. Mora, W. D. Russell, I. C. Dungy, M. Losch and L. Dusdieker, "The Iowa Infant Feeding Attitude Scale: Analysis of Reliability and Validity," Journal of Applied Social Psychology, vol. 29, no. 11, pp. $2362-2380,1999$.

[10] D. WHO/UNICEF/IFPRI/UC, "Indicators for assessing infant and young child feeding practices. Part 2: Measurement.," World Health Organization, Geneva, 2010.

[11] L. Afrose, B. Banu, K. R. Ahmed and K. Khanom, "Factors associated with knowledge about breastfeeding among female garment workers in Dhaka city," WHO South-East Asia Journal of Public Health, vol. 1, no. 3, pp. 249 - 255, 2012.

[12] Z. Khamnian, A. Azarfar, Y. Ravanshad, M. Hashemian and K. Hasanpour, "Exclusive Breastfeeding and Factors Affecting Knowledge, Attitude and Practice of Mothers in Rural and Urban Regions of East Azerbaijan, Iran," Life Science Journal, vol. 10, no. 5s, pp. 473-478, 2013.

[13] S. S.V, "Assessment of Knowledge Attitude and Practice of Breastfeeding among Mothers of Underfive in A selected Urban Slum, Bangalore, with A view to Develop Information Guide Sheet," Government college of Nursing, Bangalore, 2005.

[14] h. A. Mbwana, C. Conlon and P. V. Hurst, "Exclusive breastfeeding: Mothers' awareness and healthcare providers' practices during antenatal visits in Mvomero, Tanzania," International Journal of Nutrition and Metabolism, vol. 5, no. 3, pp. 40 - 49, 2013.

[15] S. B. Shetty and S. K. Shetty, "KAP study of factors promoting breastfeeding in nursing mothers and pregnant women," Nitte University Journal of Health Science, vol. 3, no. 3, pp. 34-35, 2013.

[16] A. M. Al-Binali, "Breastfeeding knowledge, attitude and practice among school teachers in Abha female educational district, southwestern Saudi Arabia," International Breastfeeding Journal, vol. 7, no. 10, pp. 2-6, 2012.

[17] A. J. Abdul Ameer, A.-H. M. Al-Hadi and M. M. Abdulla, "Knowledge, attitudes and practices of Iraqi mothers and family child-caring women regarding breastfeeding," Eastern Mediterranean Health Journal, vol. 14, no. 5, pp. $1003-1014,2008$.

[18] A. Ritzen, D. Johnson, B. Bekemeier and M. A. O'Hara, "Breastfeeding Survey of Washington State Pediatricians," Washington State Journal of Public Health Practice, vol. 2, no. 2, pp. 1-12, 2009.

[19] T. Amin, H. Hablas and A. Abd Al Qader, "Determinants of Initiation and Exclusivity of Breastfeeding in Al Hassa, Saudi Arabia," Breastfeeding Medicine, vol. 6, no. 2, pp. 59 -68, 2011.

[20] M. Ekambaram, V. B. B and M. A. P. Ahmed, "Knowledge, attitiude and practice of breastfeeding among postnatal mothers," Curr Pediatr Res, vol. 14, no. 2, pp. 119 -124, 2010.

[21] A. E. Tan, W. K. Choong, P. Y. Leong, W. M. Ng and S. L. Yong, "Knowledge, Attitudes and Sources of Information on Breastfeeding among Pregnant Mothers," Med \& Health, vol. 3, no. 1, pp. 30- 37, 2008.

[22] R. Chaudhary, T. Shah and S. Raja, "Knowledge and practice of mothers regarding breast feeding: a hospital based study," BPKIHS Dharan, vol. 9, no. 3, pp. 194-200, 2011.

[23] M. Inoue, C. W. Binns, Y. Katsuki and M. Ouchi, "Japanese mothers' breastfeeding knowledge and attitudes assessed by the Iowa Infant Feeding Attitudes Scale," Asia Pac J Clin Nutr, vol. 22, no. 2, pp. 261-265, 2013. 
[24] S. Chen, C. W. Binns, Y. Liu, B. Maycock, Y. Zhao and L. Tang, "Attitudes towards breastfeeding - the Iowa Infant Feeding Attitude Scale in Chinese mothers living in China and Australia," Asia Pac J Clin Nutr, vol. 22, no. 2, pp. 266-269, 2013.

[25] UNICEF, "Tracking Progress on Child and Maternal Nutrion," United Nations Children's Fund (UNICEF), New York, 2009.

[26] E. Örün, S. S. Yalçın, Y. Madendag, Z. Üstünyurt-Eras, S. Kutluk and K. Yurdakök, "Factors associated with breastfeeding initiation time in a Baby-Friendly Hospital," The Turkish Journal of Pediatrics, vol. 52, no. 1, pp. 10-16, 2010.

[27] P. S. Bobhate and S. R. Shrivastava, "Breastfeeding Practices and Factors Associated With It: A Cross Sectional Study Among Tribal Women in Khardi Primary Health Centre, Thane, India," International Journal of Public Health Research, vol. 2, no. 1, pp. 115-121, 2012.

[28] T. K. Y. Al-Hilfy, "Mothers knowledge and attitude regarding childhood survival," The Middle East Journal of Family Medicine, vol. 5, no. 1, pp. 9 -26, 2007.

[29] V. Shaili, S. Parul, K. SD, S. Jayanti, S. Anurag and N. Vipul, "A community based study on breastfeeding practices in rural area of Uttarakhand," National Journal of Community Medicine, vol. 3, no. 2, pp. 283-287, 2012.

[30] MoPHP, "Summary Report of the Family Health Survey 2003.," Ministry of Public Health and Population., Sana'a, 2003.

[31] A. A. Al-Shoshan, "Factors Affecting Mother's Choices and Decisions Related to Breast Feeding Practices and Weaning Habits," Asian Network for Scientific Information, Riyadh, Saudi Arabia, 2007

[32] L. F. Sunna, "Child Feeding Patterns and Diarrhea," Mu'tah University, Al-Karak Governorate, Jordan., 2012.

[33] H. Radwan, "Patterns and determinants of breastfeeding and complementary feeding practices of Emirati Mothers in the United Arab Emirates," BioMed Central, Public Health, vol. 13, no. 171, pp. 1-11, 2013.

[34] M. Dashti, J. A. Scott, C. A. Edwards and M. Al-Sughayer, "Determinants of breastfeeding initiation among mothers in Kuwait," International Breast Feeding Journal, vol. 5, no. 7, pp. 1-9, 2010.

[35] D. Tamiru and S. Mohammed, "Maternal knowledge of optimal breastfeeding practices and associated factors in rural communities of Arba Minch Zuria," International Journal of Nutrition and Food Sciences, vol. 2, no. 3, pp. 122-129, 2013.

[36] UNICEF \& MOPHP, "Nutrition and Mortality Survey in Low Land and Mountainous Ecological Zones of Lahj Governorate, Yemen," RELIEF International, Lahj, 2012.

[37] N. Z. Shaker, K. A. Hussein and S. I. AL-Azzawi, "Knowledge, Attitude and Practices (KAP) of Mothers toward Infant and Young Child Feeding in Primary Health Care (PHC) Centers, Erbil City," College of Nursing, Hawler Medical University, Erbil , 2009.

[38] M. M. Mubaideen and M. R. Al-Saraireh, "Breastfeeding Pattern in Selected Antenatal Care Clinics in Jordan," JRMS, vol. 13, no. 2, pp. 74-78, 2006.

[39] El-Gilany, A-H., "Breastfeeding indicators in Dakahlia Governorate," Eastern Mediterranean Health Journal, vol. 9, no. 5/6, pp. 961-973, 2003.

[40] M. Al-Madani, V. Vydelingum and J. Lawrence, "Saudi Mothers' Expected Intentions and Attitudes Toward Breast-Feeding," ICAN: Infant, Child, \& Adolescent Nutrition, vol. 2, no. 3, pp. 187 - 198, 2010.

[41] ACF-USA, "Report on the Knowledge, Attitudes and Practices (KAP) Survey, Breastfeeding and Complementary Feeding,Khatlon Oblast, Tajikistan, March-April 2007, Action Against Hunger," ACF-USA international network, 2007.

[42] M. El-Kariri and B. Kanoa, "Infant Feeding in Gaza Strip: Mother Knowledge, Attitudes and Practices," Annals of Alquds Medicine, vol. 3, pp. 58-65, 2007.

[43] M. S. Al-Jassir, B. M. El-Bashir, S. K. Moizuddin and A. A.-R. Abu-Nayan, "Infant feeding in Saudi Arabia: mothers' attitudes and practices," Eastern Mediterranean Health Journal, vol. 12, no. 1/2, pp. 6-13, 2006.

[44] M. Khassawneh, Y. Khader, Z. Amarin and A. Alkafajei, "Knowledge, attitude and practice of breastfeeding in the north of Jordan: a cross-sectional study," International Breastfeeding Journal, licensee BioMed Central Ltd., vol. 1, no. 17, pp. 1-6, 2006.

[45] B. Singh, "Knowledge, Attitude and Practice of Breast Feeding - A Case Study," European Journal of Scientific Research, vol. 40, no. 3, pp. 404-422, 2010. 
[46] S. A. M. Kotb, A. G. Mohamed, E. M. Mohamed and E. M. Abdel Khalek, "Knowledge and Practices of Working Mother about Breastfeeding and Weaning in Assiut City, Egypt," Life Science Journal, vol. 9, no. 1, pp. 803-808, 2012.

[47] Q. Zhou, K. M. Younger and J. M. Kearney, "An exploration of the knowledge and attitudes towards breastfeeding among a sample of Chinese mothers in Ireland," BMC Public Health, vol. 10, no. 722, pp. 3-11, 2010.

[48] H. Madanat, H. Farrell, R. Merrill and E. Cox, "Breastfeeding Education, Support, and Barriers among Iraqi Refugee Women in Jordan," International Electronic Journal of Health Education, vol. 10, pp. 138-149, 2007.

[49] B. Kumar, "A study of Knowledge, Attitude and Practices of Breastfeeding Among Mothers in Sullia," Rajiv Gandhi University of Health Sciences, Karnataka, Bangalore, 2011. 